WORKING PAPER NO. 8

Oct 1995

\title{
Principles, Criteria and Indicators: Applying Ockham's Razor to the People-Forestry Link
}

\author{
Carol J. Pierce Colfer with Ravi Prabhu and \\ Eva Wollenberg
}

\begin{abstract}
Summary
This concept paper addresses those elements in the people-forest interface which we perceive as critical to sustainable forest management, based on our own training and experience, as well as two field tests of the conceptual framework (in Kalimantan and Côte d'Ivoire). Initially, we define our use of important terms, like sustainability, well being/needs, and people; and make clear some of our assumptions. We briefly allude to four pertinent conceptual and policy issues, including the role of people in relation to the forest; the significance of maintaining cultural diversity; the relationships among cultural integrity, culture change, and stakeholder participation; and finally, policy issues pertaining to land use, population, and people's participation. The body of the paper discusses two principles, each with three associated criteria. An appendix lists principles, criteria, indicators and verifiers found useful in our field tests. We conclude briefly by describing future research plans, focused on refining our definitions of stakeholders, testing the importance of intergenerational access to resources and people's participation in sustainable forest management, and testing the applicability of such criteria and indicators for community forestry contexts.
\end{abstract}

CENTER FOR INTERNATIONAL FORESTRY RESEARCH

office address: Jalan CIFOR, Situ Gede, Sindangbarang, Bogor 16680, Indonesia mailing address: P.O. Box 6596 JKPWB, Jakarta 10065, Indonesia

tel.: +62 (251) 622622 fax: $+62(251) 622100$

email: cifor@egnet.com

$W W W:$ http://www.cgiar.org/cifor 


\section{The CGIAR System}

The Consultative Group on International Agricultural Research (CGIAR) is an informal association of 41 public and private sector donors that supports a network of sixteen international agricultural research institutes, CIFOR being the newest of these. The Group was established in 1971. The CGIAR Centers are part of a global agricultural research system which endeavour to apply international scientific capacity to solution of the problems of the world's disadvantaged people.

\section{CIFOR}

CIFOR was established under the CGIAR system in response to global concerns about the social, environmental and economic consequences of loss and degradation of forests. It operates through a series of highly decentralised partnerships with key institutions and/or individuals throughout the developing and industrialised worlds. The nature and duration of these partnerships are determined by the specific research problems being addressed. This research agenda is under constant review and is subject to change as the partners recognise new opportunities and problems. 
CENTER FOR INTERNATIONAL FORESTRY RESEARCH

office address: Jalan CIFOR, Situ Gede, Sindangbarang, Bogor 16680, Indonesia mailing address: P.O. Box 6596 JKPWB, Jakarta 10065, Indonesia

tel.: +62 (251) 622622 fax: $+62(251) 622100$

email: cifor@cgnet.com

$W W W:$ http://www.cgiar.org/cifor 


\title{
Principles, Criteria and Indicators: Applying Ockham's Razor to the People-Forestry Link
}

\author{
Carol J. Pierce Colfer with Ravi Prabhu and Eva Wollenberg ${ }^{1}$
}

\begin{abstract}
Summary
This concept paper addresses those elements in the people-forest interface which we perceive as critical to sustainable forest management, based on our own training and experience, as well as two field tests of the conceptual framework (in Kalimantan and Côte d'Ivoire ). Initially, we define our use of important terms, like sustainability, well being/needs, and people; and make clear some of our assumptions. We briefly allude to four pertinent conceptual and policy issues, including the role of people in relation to the forest; the significance of maintaining cultural diversity; the relationships among cultural integrity, culture change, and stakeholder participation; and finally, policy issues pertaining to land use, population, and people's participation. The body of the paper discusses two principles, each with three associated criteria. An appendix lists principles, criteria, indicators and verifiers found useful in our field tests. We conclude briefly by describing future research plans, focused on refining our definitions of stakeholders, testing the importance of inter-generational access to resources and people's participation in sustainable forest management, and testing the applicability of such criteria and indicators for community forestry contexts.
\end{abstract}

Commercial timber companies, national governments, and a variety of non-governmental organisations are struggling with the question of how to evaluate the sustainability of a timber management unit. Many would agree that one of the most intransigent series of questions pertains to people's roles in sustainable management. Answers to such questions would be valuable in the immediate, practical context of eco-labelling and certification. But they also have wider relevance in our ongoing attempt to understand human-forest interactions. This paper represents a modest, preliminary attempt to reduce the complexity of global people-forest interactions to a manageable number of principles, criteria, and (to a lesser extent at this point) indicators. Our conclusions are based on a review of the literature, as well as recent field tests of five sets of criteria and indicators (C\&I) in Indonesia and Côte d'Ivoire. ${ }^{2}$
In the following sections, we first define terms and outline assumptions, including several conceptual and policy issues of relevance to the subsequent principles, criteria and indicators. We then propose two principles, with their respective criteria, designed to reflect what we consider the most fundamental requirements for benign human involvement in sustainable forest management. A more detailed listing of specific indicators is provided in Annex 1. In the final section, we briefly outline our plans for the next phase of research.

\section{Definitions, Assumptions and Concep- tual Issues}

One of the problems in coping adequately with human issues in sustainability has been the lack of a shared vocabulary and a common conceptual framework (Gale

1 Ravi Prabhu is a forester leading the Project for the Testing of Criteria and Indicators for Sustainable Forest Management at the Center for International Forestry Research (CIFOR) in Bogor, Indonesia; Eva Wollenberg is a Natural Resource Management Specialist, also at CIFOR; Carol J. Pierce Colfer is an anthropologist working as a CIFOR consultant. We are also grateful for inputs from the social scientists on our expert field teams, particularly Heleen van Haaften, an agricultural sociologist with expertise in cross-cultural psychology, working with Tropenbos at Wageningen in the Netherlands (Côte d'Ivoire team); from Laksono, a professor of Anthropology at Gadjah Mada University in Yogyakarta, Indonesia (Kalimantan team); and from Ahui Anvo, a sociologist working with SODEFOR in Abidjan, Côte d'Ivoire.

2 The sets of criteria and indicators which were tested include Lembaga Ekolabel Indonesia (LEI), the British Soil Association's Woodmark, Rainforest Alliance's Smart Wood (USA), the German Tropenwald and a set from the Dutch Working Group of Experts on Sustainable Forest Management (DBB). 
and Cordray 1994, for instance, identify nine different views on what should be sustained). In this paper, we propose a particular vocabulary and put forth our perception of what needs, most fundamentally, to be addressed - striving always for a minimalist approach.

\section{A. Definitions}

1. "Sustainability". By only slight alteration, we can use the definition of sustainable development accepted at the Earth Summit in Rio de Janeiro (1990) for sustainable forest management:

"Sustainable forest management aims to meet the needs of the present without compromising the ability of future generations to meet their own needs."

Prabhu (1995) has suggested that the satisfaction of the following two conditions would be sufficient to indicate sustainability in the context of forest ecosystem management.

- Ecosystem integrity is ensured/maintained

- Well-being of people is maintained or enhanced

In the case of either of these definitions, we need to specify what is meant by "well-being" or "needs" and who are the relevant "people."

2. "Well-Being" or "Needs". For our purposes, we consider the following to be a fundamental set of needs contributing to people's well being, now and in the foreseeable future. ${ }^{3}$

- Security and sufficiency of access to resources: Ultimately all human life depends on this element. It therefore plays a crucial role in human-forest interactions.

- Incorporation into a network of other human beings who participate in a common cultural system: Being part of such systems is part of being human. Cultural systems have crucial functions in the enculturation of the young, insurance in times of illness or decrepitude, and myriad other human needs. They also provide a power base for protecting the group and its resources.

- Justic: Notions of what constitutes justice vary from place to place. Prakash and Thompson (1994) identified four quite different ways to interpret "fairness," for instance: proportionality (to each according to contribution), parity (equal distribution of outputs), priority (inherent rights, like rank/station) and potluck (equal chance, like a lottery). However it is interpreted in the various forests of the world, people seem to consider justice to comprise an important part of their well-being.

- Health and safety: People everywhere value their health, whether physical or mental; and seek it for themselves and their loved ones.

3. "People," Now and in the Future. We recognise the ultimate interdependence of all people in our assumptions (below). A forest dweller may be dependent on the forest for her daily fare; a settler in a nearby village may need forest-dependent environmental services; a consumer in the nation's capital may suffer if wood prices rise due to deforestation; a farmer in a distant country may depend on the forest for the rains that water his crops or for a stable climate.

Forest managers, though, are not omnipotent, and cannot be given the responsibility for ensuring the wellbeing of all humanity. Even within the forests they manage, they are unlikely to be able to affect all the important variables determining the sustainability of forest management.

It is therefore important first to reduce the responsibility of the forest manager to some reasonable level. To do that, we must define who has some interest or rights in forest management, who has a "stake" in the forest (see Colfer 1995, for a fuller definition of these issues). The most common word used in the sustainable forest management literature to designate these people (though inconsistent with the dictionary definition) is "stakeholder." Behan's (1988) discussion of "constituents" is also quite similar. He defines a forest's constituency as "the people who know about and care about" that forest.

Once the stakeholders have been defined, it will be necessary to ascertain the various rights and responsibilities among them. Recently there has been widespread recognition that forest dwellers have been disadvantaged in interactions with outsiders who come to manage the forests in which they live. ${ }^{4}$ There are both ethical and pragmatic reasons for resolving this human problem, in pursuit of sustainable forest management. Ethically, the well-being of these people,

3 Wollenberg (1995) has suggested a similar set: economic opportunity, recognition and respect for property, cultural heritage and identity, justice, and safety and health.

4 Cf. Dove (in press) and Smith and Steel (1995) for theoretical discussions of the ubiquity (and perhaps inevitability) of this kind of problem. 
as defined above, has in many cases been adversely affected. Pragmatically, when people's well-being is thus affected, there is an increased potential for conflict, forest and landscape degradation, marginalisation, and cultural disintegration. In the worst case scenario, if forest actors' situations are unacceptable to them, there may be no forest left for any would-be claimants.

To identify these forest actors, we have developed a simple technique for differentiating among stakeholders (discussed in more detail in Colfer 1995). The first step in this process is the identification of stakeholders. In the forest of East Kalimantan, we identified ten kinds of stakeholders: Dayaks, Kutai, transmigrants, forest workers, small scale entrepreneurs, company officials, government officials, environmentalists, national citizens, and consumers. In Côte d'Ivoire, we also found ten; in Bushler Bay, Washington in the United States, we identified only seven.

We provide "thumbnail sketches" of some East Kalimantan stakeholders, to illustrate the concept, recognising that stakeholders differ from place to place. Even in one location, the categories are "fuzzy sets" which may have quite permeable boundaries.

Dayaks are animists or Christians residing in forests along rivers. They tend to have occupied a definable area [though not necessarily that particular village site] for decades and sometimes centuries. They tend to have less power, money and formal education than do members of the dominant society. They have useful knowledge about their environment and sometimes sustainable indigenous forest management systems which are under-valued and misunderstood by outsiders. They also normally have some, varying, commitment to maintaining their forested environment and way of life.

Kutai are Muslim forest dwellers who practise a lifestyle in many ways similar to Dayaks. A major difference between them is the greater interest of the Kutai in commercial transactions, and their greater acceptability within the dominant society because of their Muslim religion.

Transmigrants have moved to the forest from other more densely populated contexts (Java, Timor, Flores). They are poor, with few economic alternatives. They typically come as families, intending to practise settled agriculture, often under national government sponsorship. Recent settlers are usually unfamiliar with ways to thrive in and sustain forested environments, tending more toward agricultural lifestyles. Over time they may take on or adapt some of the knowledge and practices of forest people (Fulcher 1982).

Forest workers most typically cut trees for the timber industry. The men tend to work under hazardous conditions, often with little knowledge of careful logging practices - either for their own safety or environmental protection. Most women work in the informal sector (including prostitution, with all the physical and mental health hazards that accompany that occupation). Many forest workers are far from their families and other traditional sources of social control or protection, though some may stay on as settlers after logging operations end.

Small-scale entrepreneurs may be in business or government. They have information and capital which allows them to participate in the marketing and processing of forest products. They also may engage in land speculation, hiring others to $\log$ (sometimes illegally) and/or to clear forest areas which they later claim.

Company officials are higher-echelon employees of enterprises which harvest forest products. They typically come to the forest from some other, more urban area, with little knowledge of local conditions, either human or environmental. They represent a national presence in remote, forested areas, and may have significant power over the lives of people living in the forest.

Forestry officials are employees of the nation's forestry agency. 5 They are technically responsible for forest management, yet sometimes do not have the resources (human or financial) to manage effectively. Their official mandate includes protecting the forest, and to a lesser extent, contributing to the well-being of the people.

Environmentalists are typically urban-based individuals who are concerned with forest conservation or preservation, and make efforts to influence forest management with environmental goals in mind.

National citizens have an interest in forest management largely as potential recipients of government largesse deriving from forest revenues. Development and poverty programmes can be partially financed by forest revenues.

Consumers are those who make use of forest products. Virtually all are concerned about having access to forest products, and some are concerned

5 Although the Ministry of Forestry in Indonesia considers itself to be the owner of Indonesia's forest lands, land and forest ownership is in fact quite complex and confusing, due to the presence of a series of agricultural laws acknowledging the customary (adat) rights of communities in land ownership. 
about the sustainability of forest management. They represent a potential force for sustainable forest management insofar as they are aware of the issues involved (cf. Dove 1993, for a thought-provoking critique of this reasoning with regard to non-timber forest products).

Once we have identified the major stakeholders, we need a further mechanism for identifying which of these people have significant potential, direct influence on the forest. We define these forest actors in a preliminary fashion by use of six dimensions which pertain to human impacts on sustainable forest management. These are

- proximity,

- pre-existing rights,

- dependency,

- indigenous knowledge about forest management,

- culture-forest integration, and

- $\quad$ power deficit vis-a-vis other stakeholders

Using these dimensions and a simple scoring method (1-3, on each dimension, averaged), ${ }^{6}$ we identify $<2$ as a reasonable cut-off point, thus classifying Dayaks, Kutai, transmigrants, and forest workers as "forest actors." An example of our simple scoring method is illustrated in Annex 2.

Among the forest actors, further refinement will be necessary for day to day forest management. Nurse et al. (1995), using participatory mapping techniques in Cameroon, for instance, identified different user groups, and interest groups within those user groups, with differing locally acceptable rights and responsibilities.

The method outlined above is a convenient mechanism for defining which of the stakeholders have the most pressing rights (with corresponding responsibilities) and thus constitute a sort of bottom line for stakeholder satisfaction; but it is not a carte blanche for ignoring the rest. Sustainable forestry will ultimately, and probably inevitably, involve continuing negotiation and conflict management among stakeholders. Some progress is being made on how to accomplish this in a constructive manner (see Resolve 1994, for examples from Ecuador, Bolivia and Brazil), but much remains to be done.

\section{B. Some Fundamental Assumptions}

Given the complexity of people-forest interactions, we acknowledge the probability that there are numerous unrecognised assumptions which will need further clarification as our research continues. However, outlining a few quite basic assumptions seems useful at this stage. These include:

1. That the landscape, where we are evaluating sustainability, is and will remain largely natural forest in the foreseeable future.

"Natural forest," as discussed here, can include logged forest as well as areas which are in various stages of regrowth (from spontaneous "natural" or planned human causes) or small areas that have been cleared. This assumption derives from a global perception that protecting some forested areas is in the best interests of humans. If in particular areas people do not want to protect the forest - as long as the global perception is that forests need protection-we must devise mechanisms whereby sufficient forest benefits accrue to those who live there. Trying to force forest protection has generally been shown to be ineffective (or prohibitively expensive). The principles and criteria below reflect our view that forest protection must also be perceived by local people to be in their best interests.

2. That sustainable natural forest management locally will contribute to sustainable natural forest management nationally and regionally.

Lele (1993: 33) provides a logical defence of this perspective.

3. That human systems are complex adaptive systems, intimately connected with each other and with biological systems, in a self-organising process of co-adaptation.

Complex adaptive systems are incompletely understood, but include such features as networks of inter-connected nodes, self-organisation and emergence, self-organised criticality, a dynamism between order and chaos, increasing returns, prediction and feedback (see Waldrop 1992, for a thorough exposition of the concept). We are explicitly rejecting the idea that culture change is problematic, requiring explanation, while cultural stability is not. Stability and change are aspects of cultural systems which vary in space and time.

6 The methodological problems with this simple scoring method are discussed in detail in Colfer (1995). The problem, to date, is that as methodological legitimacy increases, so does difficulty in filling in the matrix. 


\section{Conceptual and Policy Issues}

Here we begin by presenting three conceptual issues that have coloured our selection of the most critical principles and criteria. First, we describe the way in which we see the interactions between people and forests. Second we put forth some suggestions on the role of diversity of human systems in the sustainability of human life on the planet. Third we discuss the interrelationships among cultural integrity, culture change and stakeholder participation. We conclude this section with a brief discussion of three important kinds of policies that are needed to support people's benign involvement in sustainable forest management.

1. Role of People in Relation to the Forest. Most fundamentally, we view local people as part of the forest, in recognition of humanity's biological basis. People - particularly those whom we have defined as 'forest actors' - have a relationship of mutual dependence with the forest. They both contribute to and benefit from the forest. In this sense, forest actors constitute a resource, like biophysical forest resources, available for the benefit of people and forests.

This interaction between people and their environment means that people living in the forest both depend on it and act on it (Vayda et al. 1980; Vayda 1983). In recent years, there has been increasing documentation of long-standing, two-way interaction between human systems and forest ecosystems (e.g., Fairhead and Leach 1995, in Africa; Balee 1992, Roosevelt 1989 or Salick 1992, in South America). That poor people sometimes constitute a threat to sustainable forest management is widely believed and may be true (though Dove 1993, or Banuri and Marglin 1993, provide well-argued critiques of this view). The degree to which they can contribute to sustainable forest management has only recently begun to be acknowledged (Clay 1988; Colfer with Peluso and Chin in press; Posey 1992; Savyasaachi 1993).

Banuri and Marglin (1993) argue that many indigenous systems of knowledge are available to us, and if recognised and allowed to flourish, would have potentially more benign, nurturing implications for the ecosystem than does the dominant system of scientific knowledge. Be that as it may, there is a growing body of evidence to suggest that attention to the voices and perceptions of forest actors may be in both humanity's and the forests' best interests.
2. Maintenance of Cultural Diversity. There is a body of theory emerging which shows how complex adaptive systems like human cultures and ecosystems have the capacity to evolve, to increase their own complexity, to provide "increasing returns" (e.g., Barbier et al. 1994; Waldrop 1992). Researchers in a variety of disciplines have found self-organizing, creative aspects - or "emergence" - in widely differing contexts. The notion of "progress" was not dissimilar to this idea, but it tended to be uni-directional, incorporating the assumption that the West represented a higher stage of evolution or "emergence" than other cultures. This new body of theory recognises that cultures everywhere are constantly changing. This creative, evolving aspect suggests that allowing, or contributing to, the obliteration of knowledge systems, cultures or ecosystems-complex adaptive systems, par excellence - is fundamentally destructive of something of value.

Additionally, such destruction may reduce the human capacity for sustaining itself. Whereas the importance of maintaining global biodiversity has been widely accepted, there is an equally pressing need for maintaining human cultural diversity for many of the same reasons. Diversity in itself is of value (for risk reduction, for a fuller panorama of human potential, for increasing human knowledge and understanding). Human cultural diversity represents differing solutions to survival in differing contexts (Global Biodiversity Strategy 1992). It serves as a dynamic global heritage from which future generations can benefit as well as current ones. Just as we do not now know which plant species may contain the properties needed to surmount an existing or future disease, neither do we know what human cultural characteristics (knowledge, values, social organisation) may be needed in the future to sustain the human species. Enhancing the capability of a variety of cultures to flourish, changing in directions selected and monitored by their adherents, constitutes a kind of "insurance policy" for the human species (as Barbier et al. 1994 suggest with regard to biodiversity; see also Smith 1994).

3. Cultural Integrity, Culture Change, and Stakeholder Participation. Cultures are always changingthough at varying rates; and varying degrees and directions of "culture change" can affect human wellbeing, in different ways. A certain degree of cultural stability and integrity ${ }^{7}$ is important for adequate accom-

7. We are grateful to both Laksono, who emphasised cultural integrity, and Heleen van Haaften who emphasised change, for helping us to focus our attention on this issue. 
plishment of the "needs" outlined above. Yet people everywhere seem interested in improving their lives, by a wide variety of means, consistent with their own respective goals and values. ${ }^{8}$ One element in achieving sustainability of human systems involves a healthy balance between these two forces (cf. Waldrop 1992 whose book on complexity is subtitled "the Emerging Science at the Edge of Order and Chaos").

The diversity of human conditions implied by perpetual cultural change, added to the cultural diversity that characterises the globe at any point in time, suggests a near-infinite range of human conditions. Managing culture change externally, though continually attempted, is logically rather impractical. There are an unwieldy number of cultures, varying dramatically over time, with multitudinous intra-cultural variations among individuals and groups.

There are also vast - though varying - areas of human life which have always been managed locally. ${ }^{9}$ The "informal sector" (e.g., small-scale trade in timber and non-timber forest products, home-based food and fibre-processing activities, gathering of forest foods and medicinal plants) is one ubiquitous kind of local management. Women's and children's lives provide another example, invisible to official forest managersand thus locally managed.

Forestry or timber company officials are unlikely to have the expertise to examine local cultures in sufficient detail to make informed decisions on the people's behalf; Alternatively, putting a trained social scientist in every village is unrealistic. Local people, on the other hand, have an intimate knowledge of their own systems (including an intuitive feel for the appropriate rate and direction of change); they seem likely to have the motivation to collaborate in forest management- providing this important information - if they have a real voice.

Sustainable forest management may require - if cultural integrity and the associated well being of people is to be maintained - active involvement of stakeholders, in varying degrees, in forest management decisions. Without it, people may lose their stake in the forest and hence their commitment to forest stew- ardship (in their own and their children's interests, as well as that of the environment). This can in turn result in a downward spiral of human and environmental well-being (see Criterion 1.3, below, for further discussion of these interrelationships).

4. Policy Issues Before addressing into the principles and criteria that we consider most fundamental at the forest-management unit level, we must give brief attention to the importance of supportive national policies if the practices that we consider indicative of sustainable management are to be implemented. The most critical of these include land use, population and people's participation.

Different land uses obviously adversely affect forests in different ways, and thus need monitoring. Timber companies may harvest timber in environmentally damaging ways; urban entrepreneurs may illegally clear forests on speculation; settlers may intensively manage soils for which such a use is not sustainable; shifting cultivators may cut fields in areas defined by others as protected areas; etc. The uses to which people put the land must be considered in developing appropriate policies for forest management.

Similarly, where there is evidence that population levels are adversely affecting the environment (such as in many government-sponsored settlement programs), governments must be ready with policies that encourage population stabilisation. These can take the form of voluntary family planning programmes and/or mechanisms to discourage in-migration.

Since we are concerned with the well-being of both men and women, the implications of reduced family size for women's health and life opportunities should not be overlooked. Globally and historically, women who bear fewer children tend to have greater education and employment opportunities, better health, and greater participation in decision making at various levels. Women's personal interest (even in extremely pro-natalist environments like much of the Middle East) in controlling their fertility has been widely documented. ${ }^{10}$ Insofar as local women's personal desire

8 Forestry researchers, social scientists, officials, timber company managers, environmentalists, small-scale traders, as well as forest community members, participate in one culture or another. Each of these kinds of people participate in cultural systems which are affected by this tension. Although we emphasise the needs and potential contribution of forest-dwelling communities here, many of the observations apply on a reduced scale to other stakeholders as well.

9 The process of "modernisation" or "development" involved, for several decades, a wholesale attack on local institutions including management, which were viewed as "backward" and "primitive" by definition. In recent years, there has been a tendency toward more balance, recognising that many local practices are neutral or beneficial, even if different from the practices of the powerful.

10 There are often conditions, such as a family's need for more labour or a tribe's interest in maintaining its hegemony through population increase, which influence women's ability to act on their interest in controlling their fertility. In the Middle East, women commonly fear (with reason) that their husbands will take another wife if they do not produce children at a steady rate. 
for birth control can contribute to decreasing long-term local demands on forests - thus contributing both to the immediate well being of people and the forest- it pertains directly to sustainable forest management.

The importance of policies favouring increased participation by stakeholders was implied above. Although many argue for people's participation on ideological or ethical grounds, there are also practical reasons for involving people directly in forest management. Participation can serve as a mechanism for accomplishing four important management needs: converting conflict about forest resources to mutual accommodation; providing knowledge (including indigenous and ecological) for use in forest management; reducing non-compliance with forest resource use regulations; and controlling the speed and direction of changes in local forest-based lifestyles.

\section{Principles, Criteria and Indicators}

These three, hierarchically organised concepts are widely used in the growing literature on sustainable forest management, certification and eco-labelling of timber (ITTO 1992; Rainforest Alliance 1993; Heuveldop 1994; Soil Association 1994; Forest Stewardship Council 1994). For our purposes we have followed the Oxford Dictionary of Current English (1987) and defined a principle as "a fundamental truth or law as the basis of reasoning or action." Principles, then, are stated as imperatives.

We also use the dictionary definition of criterion: "a principle or standard that a thing is judged by." FAO (1995) has a definition of "criterion" focused on forest management which is also consistent with our usage: "identified elements of sustainability against which forest management can be assessed." Criteria are phrased as conditions (which must be met for a forest to be judged as "sustainably managed").

\section{A. Two Principles and Six Criteria}

We have identified two principles which we consider fundamental to benign human involvement in sustainable forest management.

Principle 1 - Forest management should maintain or enhance the flow of benefits from forest resources, with access generally perceived as just by all stakeholders.

Principle 2 - The voice of all stakeholders must inform forest management.
These recognise, in "forest resources," the importance of both the physical and economic basis of human life on the one hand, and the cognitive, normative and symbolic elements on the other. There have been decades of debate within the social sciences about the priority of one or the other of these two aspects of the human condition (Harris 1968 provides a somewhat dated, but comprehensive review of this literature from a "techno-environmental" perspective). The view here is that both "hard" and "soft" elements are important for human well-being and thus for the sustainability of forests. Having a voice in forest management allows stakeholders to make their wishes about these resources known.

We then identify criteria which constitute conditions showing compliance with the principles. We suggest indicators which show (in some cases, partially) that the condition has been met (summarised in the appendix). In some cases, we indicate "verifiers" which to date represent examples of how an indicator might be verified.

Any attempt to provide a conceptual framework for sustainable forest management will require the application of some value judgements (such as our expressed interest in "justice"). We have found a general tendency for such value judgements to be justifiable, to varying degrees, on pragmatic grounds as well. Although an effort is made in the following presentation to identify a minimal set of crucial features of sustainable systems, we recognise that this paper constitutes an early step in a long and complex process. Part of that process will involve further testing and refinement of the criteria and indicators (C\&I).

Additionally, the principles, criteria and indicators a) are built on the assumptions listed earlier, and b) must be taken as a whole. There is interdependence among the criteria such that, for instance, forest actors' access to resources must be balanced by appropriate mechanisms for monitoring and control. Participation in forest management is likely to be a parody if forest actors do not have secure access to the resources in question.

\section{Principle 1 - Forest management should main- tain or enhance the flow of benefits from forest resources, with access generally perceived as just by all stakeholders}

This principle addresses the issue of maintenance and fair apportionment of goods and services among stakeholders. If adhered to, it guarantees forest actors' security and sufficiency of access to resources over time, 
enhances their access to health, safety, cultural integrity and other elements of human well-being, and provides a power base for dealing with other stakeholders. There is ample evidence that many forest actors people with the greatest opportunity and potential to degrade and/or sustainably manage the forest - have not been fairly treated with regard to access to forest resources.

Other stakeholders also have legitimate claims which must be negotiated. This principle recognizes the claims of other stakeholders- such as government, private industry, environmentalists - to resource access that they consider fair as well. The existence of multiple stakeholders with legitimate and varying claims obviously implies, as mentioned earlier, a process of communication, negotiation and conflict resolution for forests to be sustainably managed. Our second principle addresses this issue.

Each of the three criteria listed below has been selected, based on considerable anecdotal and case study evidence. Each has been proposed as an appropriate criterion in sustainable forest management in one or more sets of criteria and indicators. There has been further development over the course of our testing by teams of experts, in two countries (Indonesia and Côte d'Ivoire). The C\&I remain, to some extent however, hypotheses in need of further testing.

Criterion 1.1 Forest actors' current and inter-generational access to resources is secure. This criterion is based on two pragmatic suppositions: That people are more likely to manifest stewardship toward forests from which they derive benefit; and that people tend to be more willing to sacrifice immediate gain - from activities that may result in forest degradation - when they are certain their children will benefit (cf. Palmer 1993, on Maine fishers). The accuracy of these suppositions, though widely accepted on the basis of anecdotal evidence, in fact begs further verification.11

An ethical consideration, based on justice, reinforces the importance of this criterion. "Forest actors" are defined as (among other things) people who have resided in and managed an area for long periods of time and have pre-existing claims and responsibilities in that area, both for themselves and for their descendants. Although their claims are not absolute, ${ }^{12}$ they should have some priority over those of other stakeholders.

In this discussion we have avoided specifying a particular kind of tenure system, ${ }^{13}$ because a variety of systems could fulfill the central requirement of this principle: that people feel secure and comfortable that they and their children can continue to use the resources that have been available to them and in which they have a personal investment. We explicitly make no assumption that the claims of the state necessarily supersede those of local communities; we argue instead that conflicting claims will have to be clarified by a process of negotiation and conflict resolution.

Criterion 1.2 Forest actors have a reasonable share in the economic benefits derived from forest use. This criterion is based on our perception, again supported by considerable case-study evidence, that inadequacy of resources can force people to degrade forest resources. Perceptions of unfair distribution of benefits can stimulate purposeful, retaliatory degradation of forest resources as well as other kinds of undesirable conflict.

From a more positive perspective, people who have adequate access to resources are likely to be able to fulfill their other needs, in accordance with their wishes, thus enhancing their well being, in terms of health, education, and other desired goods and services. Again, there is an ethical element pertaining to justice among stakeholders.

Criterion 1.3 The health of forest actors, their cultures and the forest is acceptable to all stakeholders. Maintaining the flow of benefits from resources requires that forest health be maintained. Insofar as human beings are part of the forest (and implicated in sustainable forest management), their health is also important. Indeed we see a strong interdependence among the well-being of forest actors, their

11 As currently envisioned, Phase II of the project "Testing Criteria and Indicators for Sustainable Management of Forests" will address such issues.

12 This concept is not uncommon. Conditional rights to land are familiar to forest actors in Borneo, for instance, where many communities retain some residual rights, even in otherwise privately held resources (Appell 1986; Ngo 1990; Colfer with Dudley 1993; Peluso 1994). In Côte d'Ivoire, we found a willingness to accept needy outsiders and give them access to land, even when such pressure resulted in environmental degradation (Riezebos et al. 1994; SODEFOR 1994; van Haaften 1995).

13 Tenure is defined, following Meriam-Webster's dictionary (1994) as "the act, right, manner, or term of holding something (as a landed property, a position, or an office)." It therefore incorporates, in the context of forest management, a variety of combinations of use rights, stewardship, communal and individual ownership, state management, etc. This generality seems appropriate, given global variation. 
cultures and the forest. Because of the dependence of the people upon the forest, its health is, at some level, important to them. The health of the forest in turn is dependent on human well-being, since poor and unhealthy human beings, or too many human beings, may need to ravage the forest to survive.

Similarly human culture affects human action, which in turn can enhance or degrade forest health via such mechanisms as sustainable management systems or useful indigenous knowledge on the one hand, or exploitative attitudes and practices on the other. Forest actors, who by definition have a strong forest-culture link, long-term rights in the area, and considerable knowledge of and dependence on the forest, are likely to have important elements in their forest management systems which sustain those systems. ${ }^{14}$ But changing circumstances (access to markets, opportunities for medical care and education, desire for consumer goods, in-migration, changing gender roles, technological changes) can have dramatic effects on cultures. For this reason the degree and conditions under which forest actors practise sustainable forest management need further investigation.

Cultures also affect human well-being in other ways 15 and thus "cultural health" needs monitoring in its own right. Culture, as a dynamic mode of adaptation, provides human beings with (malleable) patterns for communication, subsistence, division of labour, inheritance patterns, enculturation of the young, old age security, values, etc. - all critical to human wellbeing. Indeed, even what the "health" of people and forests means is defined culturally. In contributing to human well being ${ }^{16}$ these functions contribute to sustainable forest management.

\section{Principle 2: The voice of all stakeholders must inform forest management}

This principle specifies both an enhanced voice for various stakeholders and increased integration of their thoughts and preferences into forest management. It supports the rights of those concerned about and making use of the forest to express their views and influence forest management (following Behan 1988). This is important for several reasons. In many areas, forest actors particularly have had few opportunities to be heard or integrate their views into formal forest management. Having a legitimised voice provides a mechanism for enunciating their traditional rights and responsibilities and their existing systems of forest management; for protecting the rights identified; for gaining access to a share in the benefits of forest exploitation; for integrating their own knowledge, experience, and preferences into overall forest management (thus reducing marginalisation, van Haaften 1995); and, by all these means, for protecting their children's future.

The right to a voice is also important for other stakeholders. In the United States, for instance, environmentalists from New York City may have strong opinions and attachment to the Olympic National Forest in the western State of Washington thousands of kilometres away; similarly Jakarta-based environmentalists have strong views on forest management in distant Borneo. The respective forestry agencies obviously have pertinent input on forest management. National citizens may have legitimate concerns about how their taxes are being spent or how forest revenues are being collected. Without such a voice (because of the diversity of human systems), no widely applicable mechanism exists by which forest managers can effectively integrate the legitimate forest uses of various stakeholders into sustainable management.

As with the previous three criteria, the following three are based on anecdotal and case materials, as well as field tests in Indonesia and Côte d'Ivoire. Just as we cannot yet "prove" that fair access among stakeholders to resources is critical to sustainable forest management, neither have we been able to prove the importance of giving stakeholders a strong voice in forest management. We present our reasoning below, as each criterion is introduced. Our plan is to devote considerable time and effort to further testing of these C\&I to determine where and how our conceptual framework needs improvement.

Criterion 2.1 All stakeholders have an acknowledged right and means to participate in equitable forest management. The importance of cultural systems for people's well-being, combined with the nearly infinite diversity of such systems in time and space, makes obvious the crucial role of participation in sustainable forest management. To be able to address stakeholders' concerns, forest managers must know what those concerns are.

The absence of such feedback to local forest

14 See Palmer (1993) for a counter example from Newfoundland's fisheries.

15 Winthrop's first definition (of many) of culture (1991) is "That set of capacities which distinguishes Homo sapiens as a species and which is fundamental to its mode of adaptation."

16 There are oppressive and unjust elements in all cultures; but conversely human beings universally have difficulty thriving when their cultural sytems have been disrupted. 
managers has been most obvious in the case of forest actors. Without forest actors' active participation ${ }^{17}$ in forest management, no viable mechanism has been identified for communicating relevant aspects of their cultures to other stakeholders (and to a lesser extent vice versa).

From the standpoint of forest actors, one of the most crucial functions of participation is in providing a means for local people to control the speed and direction of changes in their forest-based lifestyle. Supporting their right to speak out can help them to protect their existing way of life (enhancing cultural diversity, protecting cultural and natural-resource integrity), insofar as they want to, and to alter it in ways they consider desirable (cf. Oksa 1993 on Finnish people and forests). In so doing, it can also reduce such adverse psychological consequences as stress and marginalisation, as well as related physical health problems (van Haaften 1995). Active participation by stakeholders in forest management provides a mechanism for dealing with cultural diversity and with the continually changing interface between people and forests.

Criterion 2.2 - Resource managers cooperate to assimilate differing management models. This criterion derives from the increasing recognition that forest actors often have natural-resource management systems that are, or have been, viable. Although generalising about the global situation in this regard is dangerous, there is a growing sense that conventional science can learn from indigenous systems. Pro-active attempts to integrate indigenous systems with more conventional management models may also be helpful in minimising conflicts, as well as leading to better overall management.

The other side of this coin pertains to the well-being of forest actors. Insofar as forests are managed cooperatively with other stakeholders, meshing management systems in mutually beneficial ways, the activities of other stakeholders will be less disruptive to forest actors and their existing systems.

Criterion 2.3 - Mechanisms for control of access to desired local resources is supported by all stakeholders. Without the support of stakeholders, efforts to control access to resources are unlikely to succeed. Forestry officials in charge of forest protection may not support existing mechanisms for control of access (e.g., by giving forest concessions based on cronyism or failing to enforce forestry regulations). Forest actors may continue to harvest forbidden species or in protected areas, feeling that their own rights have been usurped. Sustainable forest management requires that these kinds of problems be resolved in such a way that stakeholders support existing mechanisms for control, or develop new, more-viable ones.

\section{Conclusions}

In this paper, after specifying some important assumptions, definitions, and interactions among factors, we have concentrated on those principles and criteria of sustainable forest management (successfully applied in two field tests) that we consider most critical. We have presented indicators that, though not yet truly satisfactory, have been applied or emerged in the field testing contexts.

Recognising that these views on people-forest interactions need further investigation and refinement, we are planning a second research phase. In that work, we will focus specifically on a) the improved identification of forest actors; b) people's security of inter-generational access to resources, and c) the effects of people's participation in forest management. We hope also to investigate the nature of human wellbeing, the impact of income generation on conservation areas, and how these C\&I do or do not pertain to community forestry.

In trying to refine our definitions of forest actors and our understanding of participation and inter-gener ational acess to resources, we will be selecting areas that vary along several important continua, including:

- islands of people in a sea of forest vis-a-vis islands of forest in a sea of people;

- existing security of intergenerational access to resources vs. relative insecurity about such access;

- observable participation of local people $v s$. absence/paucity of participation; and

- policies favoring vs. those opposing local participation and local rights to resources.

In this work, most fundamentally, we hope to gain a clearer understanding of the links among inter-generational access to resources, participation, policies, and forest management; and to improve the definition and measurement of criteria and indicators for sustainable forest management.

17 Green (1986) defines active participation (in a health context) as "...the conscious and intentional involvement of the individual or population in question, as distinct from the passive engagement of the individual or population in each of the activities or processes that follow": identifying their own goals or needs, setting their own priorities among goals or needs, controlling the implementation of programs or solutions, and evaluating or otherwise obtaining feedback on their own progress. Obviously the involvement of distinct stakeholder groups in forest management requires varying degrees of negotiations, perhaps at each of these steps. 


\section{Bibliography}

Appell, G. 1986. Kayan land tenure and the distribution of devolvable usufruct in Borneo. Borneo Research Bulletin 18: 119-130.

Balee, W. 1992. People of the fallow: a historical ecology of foraging in lowland South America. In K.H. Redford and C. Padoch (eds.), Conservation of Neotropical Forests: Working from Traditional Resource Use. Columbia University Press, New York. pp. 35-57.

Banuri, T. and F.A. Marglin. (eds.) 1993. Who will Save the Forests?: Knowledge, Power and Environmental Destruction. Zed Books, London.

Barbier, Edward B., Joanne C. Burgess and Carl Folke (1994). Paradise Lost? The Ecological Economics of Biodiversity. London: Earthscan.

Behan, R.W. 1988. A plea for constituency-based management. American Forests (July/August): 46-48.

Clay, J.W. 1988. Indigenous People and Tropical Forests. Cultural Survival, Inc., Cambridge, Mass.

Colfer, C.J. Pierce 1995. Who counts most in sustainable forest management? CIFOR Working Paper No 7. Project to Evaluate Criteria and Indicators for Sustainable Forest Management. CIFOR, Bogor, Indonesia.

Colfer, C.J. Pierce with R.G. Dudley. 1993. Shifting Cultivators of Indonesia: Marauders or Managers of the Forest? FAO Community Forestry Case Study Series No. 6. FAO, Rome.

Colfer, C.J. Pierce with N. Peluso and Chin See Chung. In press. Beyond Slash and Burn: Lessons from the Kenyah on Management of Borneo's Rain Forests. New York Botanical Garden Press, New York.

Dove, M. 1993. A revisionist view of tropical deforestation and development. Environmental Conservation 20: $17-24$.

Dove, M. In press. Center, periphery and biodiversity: a paradox of governance and a developmental challenge. In: S. Brush and D. Stabinsky (eds.), Intellectual Property Rights and Indigenous Knowledge. Island Press, Washington, D.C.

Fairhead, J. and M. Leach. 1995. Whose forest? Modern conservation and historical land use in Guinea's Ziama Reserve. Rural Development Forestry Network Paper 18c. ODI, Regent's College, Regent's Park, London.

FAO (1995). Expert Meeting on Harmonisation of Criteria and Indicators for Sustainable Forest Management, Rome, Italy, 13-16 February 1995.

Forest Stewardship Council. 1994. Forest Stewardship Council Ratification Documents (July). Oaxaca, Mexico.

Fulcher, M. 1982. Dayak and transmigration communities in East Kalimantan. Borneo Research Bulletin 14(1): 14-24.

Gale, R.P. and S.M. Cordray. 1994. Making sense of sustainability: nine answers to "What should be sustained?" Rural Sociology 59(2): 311-332.

Global Biodiversity Strategy. 1992. WRI, IUCN, UNEP, Washington, D.C.

Green, L. 1986. The theory of participation: a qualitative analysis of its expression in national and international health policies. Advances in Health Education and Promotion 1(A): 211-236.

van Haaften, H. 1995. Final report/diary. Prepared for CIFOR's project on Testing Criteria and Indicators for Sustainable Forest Management, Côte d'Ivoire.

Harris, M. 1968. The Rise of Anthropological Theory: A History of Theories of Culture. Thomas Y. Crowell, New York.

Heuveldop, J. 1994. Assessment of Sustainable Tropical Forest Management. Kommissionsverlag Max Wiedebusch, Hamburg.

ITTO. 1992. Criteria for the Measurement of Sustainable Tropical Forest Management. International Tropical Timber Organization, Yokohama, Japan.

Lele, S. 1993. Sustainability: a plural, multi-dimensional approach. Submitted to Ecological Economics (January).

Ngo, M. 1995 in press. Ambiguity in property rights: lessons from the Kayan of Kalimantan. In C. Padoch and N. Peluso (eds.), Borneo in Transition: People, Forests, Conservation and Development. New York Botanical Gardens.

Nurse, M. C., C. R. McKay, J. T. Young and C. A. Asanga. 1995. Biodiversity conservation through community forestry, in the montane forests of Cameroon. Rural Development Forestry Network Paper 18d. ODI, Regent's College, Regent's Park, London, Winter 1994-Spring 1995: 14-19. 
Oksa, J. 1993. The benign encounter: the great move and the role of the State in Finnish forests. In: T. Banuri and F.A. Marglin (eds.), Who will Save the Forests?: Knowledge, Power and Environmental Destruction. Zed Books, London. pp. 24-52.

Oxford Dictionary of Current English (1987). Oxford University Press, New York.

Palmer, C. 1993. Folk management, 'soft evolutionism,' and fishers' motives: implications for the regulation of the lobster fisheries of Maine and Newfoundland. Human Organization 52(4): 414-420.

Peluso, N. 1993. The Impact of Social and Environmental Change on Forest Management: A Case Study from West Kalimantan, Indonesia. FAO Community Forestry Case Study Series No. 8.

Posey, D. 1992. Interpreting and applying the "reality" of indigenous concepts: what is necessary to learn from the natives? In: K.H. Redford and C. Padoch (eds.), Conservation of Neotropical Forests: Working from Traditional Resource Use. Columbia University Press, New York. pp. 21-34.

Prabhu, R. 1995. A conceptual framework for a system to evaluate the sustainability of forest ecosystem management: a discussion paper. CIFOR internal document.

Prakash, S. and M. Thompson. 1994. Institutions and transactions: the risk and fairness approach to environmental economics. Proposal submitted to CIFOR (November).

Resolve. 1994. The Role of Alternative Conflict Management in Community Forestry. FAO, Community Forestry Programme, Rome.

Riezebos, E.P., A.P. Vooren and J.L. Guillaumet. (eds.) 1994. Le Parc National de Tai, Côte d'Ivoire. La Fondation Tropenbos Series 8, Wageningen

Roosevelt, A. 1989. Resource management in Amazonia before the conquest: beyond ethnographic projection. Advances in Economic Botany 7: 30-62.

Salick, J. 1992. Amuesha forest use and management: an integration of indigenous use and natural forest management. In K.H. Redford and C. Padoch (eds.), Conservation of Neotropical Forests: Working from Traditional Resource Use. Columbia University Press, New York. pp. 305-332.

Savyasaachi. 1993. An alternative system of knowledge: fields and forests in Abujhmarh. In: T. Banuri and F.A. Marglin (eds.), Who will Save the Forests?: Knowledge, Power and Environmental Destruction. Zed Books, London. pp. 52-79.

Smith, C.L. 1994. Connecting cultural and biological diversity in restoring northwest salmon. Fisheries 19: 20-26.

Smith, C.L. and B.S. Steel. 1995. Core-periphery relationships of resource-based communities. Journal of the Community Development Society 26(1): 52-70.

SODEFOR. 1994. Plan d'Amenagement de la Forêt Classée de la Bossematié (22,200 ha) 1995-2014. Abengourou, Cote d'Ivoire.

Soil Association (1994). Responsible Forestry Standards (February). United Kingdom.

Vayda, A.P. 1983. Progressive contextualization: methods for research human ecology. Human Ecology 11(3): 265-281.

Vayda, A.P., C.J. Pierce Colfer and M. Brotokusumo. 1980. Interactions between people and forests in East Kalimantan. Impact of Science on Society 30(3): 179-190.

Waldrop, M.M. 1992. Complexity: The Emerging Science at the Edge of Order and Chaos. Touchstone Books(Simon and Schuster), New York.

Webster's Third New International Dictionary (1993). Merriam-Webster, Inc., Springfield, Mass.

Winthrop, R. H. 1991. Dictionary of Concepts in Cultural Anthropology. Greenwood Press, Westport, Conn. Wollenberg, E. 1995. Social dimensions of sustainability. Proposal to the Ford Foundation. 


\section{Annex 1. A Summary of Principles, Criteria, Indicators and Verifiers pertaining to People's Roles in Sustainable Forest Management}

\begin{tabular}{|l|l|l|l|l|}
\hline P & C & I & V & Principles, Criteria, Indicators, and Verifiers \\
\hline
\end{tabular}

\begin{tabular}{|c|c|c|c|c|}
\hline 1 & & & & $\begin{array}{l}\text { Forest management should maintain or enhance the flow of } \\
\text { benefits from forest resources, with access generally perceived as } \\
\text { just by all stakeholders }\end{array}$ \\
\hline & 1.1 & $\begin{array}{l}1.1 .1 \\
1.1 .2 \\
1.1 .3 \\
1.1 .4\end{array}$ & $\begin{array}{l}1.1 .4 .1 \\
1.1 .4 .2 \\
1.1 .4 .3 \\
1.1 .4 .4\end{array}$ & $\begin{array}{l}\text { Forest actors' current and inter-generational access to resources is } \\
\text { secure. } \\
\text { Inter-generational tenure and/or use rights to land/forest have been assessed } \\
\text { and delineated. } \\
\text { Tenure and use rights are clear to all stakeholders, including forest women and } \\
\text { men. } \\
\text { Effective mechanisms for resource management and conflict resolution exist, } \\
\text { available to all stakeholders. } \\
\text { Forest actors feel comfortable about the security of their rights. } \\
\text { Little or no decrease in access to commonly used forest products. } \\
\text { Little or no reduced access to sacred or culturally important sites. } \\
\text { Few or no rumurs about impending land grabs. } \\
\text { Few or no attempts to reinforce land security. }\end{array}$ \\
\hline & 1.2 & $\begin{array}{l}1.2 .1 \\
1.2 .2\end{array}$ & $\begin{array}{l}1.2 .2 .1 \\
1.2 .2 .2 \\
1.2 .2 .3 \\
1.2 .3 .1 \\
1.2 .3 .2 \\
1.2 .3 .3 \\
1.2 .4 .1 \\
1.2 .4 .2 \\
1.2 .4 .3\end{array}$ & $\begin{array}{l}\text { Forest actors have a reasonable share in the economic benefits } \\
\text { derived from forest use. } \\
\text { Economic supplements and opportunities for forest actors are increasingly } \\
\text { available. } \\
\text { Fair and effective mechanisms exist for sharing revenues from forest } \\
\text { exploitation with forest actors. } \\
\text { Wages and other benefits conform to ILO standards. } \\
\text { Damages are compensated in a fair manner. } \\
\text { Local infrastructure is enhanced due to forest management. } \\
\text { Women's and men's incomes (or other measure of improved standard of living) } \\
\text { have increased since commercial forest use began. } \\
\text { Change in number of radios, televisions, satellite dishes, or other consumer } \\
\text { goods in communities. } \\
\text { Change in incomes and/or health statistics (infant mortality, malnutrition } \\
\text { rates) compiled in company or community records. } \\
\text { Changes in land/person ratios. } \\
\text { Forest actors (men and women) have significant opportunities to work and } \\
\text { receive training under company auspices without discrimination. } \\
\text { Ethnic composition, gender and/or origin of workers at varying levels (from } \\
\text { records, observation). } \\
\text { Number of training programmes held and who attended. } \\
\text { Promotional records by ethnicity, gender, and origin. }\end{array}$ \\
\hline
\end{tabular}




\begin{tabular}{|c|c|c|c|c|}
\hline & 1.3 & $\begin{array}{l}1.3 .3 \\
1.3 .4\end{array}$ & $\begin{array}{l}1.3 .4 .1 \\
1.3 .4 .2 \\
1.3 .4 .3\end{array}$ & $\begin{array}{l}\text { The health of forest actors, cultures and the forest is acceptable to } \\
\text { all stakeholders } \\
\text { Environmental conditions affected by human uses are stable or improving. } \\
\text { Cycle of shifting cultivation is adequate. } \\
\text { In-migration and/or natural population increase are in harmony with } \\
\text { maintaining the forest. } \\
\text { Ready (voluntary) access to birth control. } \\
\text { Governmental development programmes are monitored for adverse environmental impacts. } \\
\text { Increases in conflicts regarding natural resources can be satisfactorily } \\
\text { explained by stakeholders. } \\
\text { The relationship between forest management and human health is recognised. } \\
\text { Forest managers accept responsibility for notifying public health authorities regarding } \\
\text { illnesses related to forest management. } \\
\text { Nutritional status is adequate among local populations. } \\
\text { Forestry employers follow ILO working and safety conditions and take responsibility for } \\
\text { the forest-related health risks of workers. } \\
\text { The relationship between forest maintenance and human culture is } \\
\text { acknowledged as important. } \\
\text { Forest managers can explain links between relevant human cultures and the local forest. } \\
\text { Forest management plans reflect care in handling human cultural issues. } \\
\text { There is no significant increase in signs of cultural disintegration. }\end{array}$ \\
\hline 2 & & & & The voice of all stakeholders must inform forest management \\
\hline & 2.1 & 2.1 .1 & $\begin{array}{l}2.1 .1 .1 \\
2.1 .1 .2 \\
2.1 .1 .3 \\
2.1 .1 .4\end{array}$ & $\begin{array}{l}\text { All stakeholders have an acknowledged right and means to } \\
\text { participate in equitable forest management. } \\
\text { Effective mechanisms exist for two-way communication related to forest } \\
\text { management among stakeholders. } \\
\text { Forestry agents and/or specified company personnel have responsibility to communicate } \\
\text { with the diverse groups of forest actors, and use local languages. } \\
\text { All stakeholders have an acknowledged right and means to participate in equitable forest } \\
\text { management. } \\
\text { Stakeholders meet formally and informally with satisfactory frequency and quality. } \\
\text { Local population respects and values the contributions of other stakeholders (such as } \\
\text { company or forestry officials). }\end{array}$ \\
\hline & 2.2 & 2.2.1 & $\begin{array}{l}2.2 .1 .1 \\
2.2 .1 .2 \\
2.2 .2 .1 \\
2.2 .2 .2 \\
2.2 .2 .3\end{array}$ & $\begin{array}{l}\text { Resource managers co-operate to assimilate differing management } \\
\text { models } \\
\text { Forest use reflects the necessary complementarities and compromises among } \\
\text { stakeholders. } \\
\text { Plans/maps exist showing such integration. } \\
\text { Management of NTFP reflects consultation with stakeholders. } \\
\text { Stakeholders have detailed, reciprocal knowledge pertaining to forest resources } \\
\text { and gender roles, as well as forest management plans prior to implementation. } \\
\text { Updated plans, baseline studies and maps are widely available, outlining logging details } \\
\text { like cutting areas and road construction, with timing. } \\
\text { Existence of baseline studies of local human systems. } \\
\text { Management staff recognise the existence of other stakeholders and their rights. } \\
\text { Effective mechanisms exist for mutual monitoring when co-operative plans } \\
\text { have been made and appropriate sanctions for non-compliance. }\end{array}$ \\
\hline
\end{tabular}




\begin{tabular}{|l|l|l|l|}
\hline 2.3 & 2.3.1 & 2.3.2 & $\begin{array}{l}\text { Mechanisms for control of access to desired local resources is } \\
\text { supported by all stakeholders. } \\
\text { Agreement exists on rights and responsibilities of relevant stakeholders. } \\
\text { Level of conflict is understood and acceptable to stakeholders. } \\
\text { Effective and acceptable local mechanisms exist to determine guilt and punish } \\
\text { offenders equitably when rules are transgressed. } \\
\text { Specific measures, used in times of conflict, are available to and can be explained by all } \\
\text { stakeholders. } \\
\text { Evidence exists for regular mutual monitoring. } \\
\text { Local NGO's are available and involved in activities to support forest actors. }\end{array}$ \\
\hline 2.3 .2 .1 & 2.3 .2 .3 & \\
\hline
\end{tabular}




\section{Annex 2. Sample Matrix for Identifying Forest Actors}

Stakeholder Traits - East Kalimantan, Indonesia (Borneo)

\begin{tabular}{|c|c|c|c|c|c|c|c|}
\hline \multirow{2}{*}{$\begin{array}{l}\text { "STAKE- } \\
\text { HOLDERS" }\end{array}$} & \multicolumn{7}{|c|}{ Dimensions } \\
\hline & Proximity & $\begin{array}{l}\text { Pre-existing } \\
\text { Rights }\end{array}$ & Dependency & $\begin{array}{l}\text { Indigenous } \\
\text { Knowledge }\end{array}$ & $\begin{array}{l}\text { Culture/ } \\
\text { Forest } \\
\text { Integration }\end{array}$ & $\begin{array}{l}\text { Power } \\
\text { Deficit }\end{array}$ & VALUE \\
\hline Dayak & 1 & 1 & 1 & 1 & 1 & 1 & 1.00 \\
\hline Kutai & 1 & 1 & 1 & 1 & 1 & 1 & 1.00 \\
\hline Transmigrant & 1 & var. & 1 & var. & var. & 1 & 1.00 \\
\hline Forest Workers & 1 & 3 & 1 & var. & var. & 1 & 1.50 \\
\hline $\begin{array}{l}\text { Small Scale } \\
\text { Enterpren. }\end{array}$ & 2 & var. & 2 & 2 & 2 & 2 & 2.00 \\
\hline $\begin{array}{l}\text { Company } \\
\text { Officials }\end{array}$ & 2 & 3 & 1 & 3 & 3 & 3 & 2.50 \\
\hline $\begin{array}{l}\text { Forestry } \\
\text { Officials }\end{array}$ & 3 & 3 & 1 & 3 & 3 & 3 & 2.67 \\
\hline $\begin{array}{l}\text { Environ- } \\
\text { mentalists }\end{array}$ & 3 & 3 & 2 & 3 & 2 & 3 & 2.67 \\
\hline $\begin{array}{l}\text { National } \\
\text { Citizens }\end{array}$ & 3 & 3 & 2 & 3 & 3 & var. & 2.80 \\
\hline Consumers & 3 & 3 & 3 & 3 & 3 & var. & 3.00 \\
\hline
\end{tabular}

